\title{
PRODUÇÃO FECAL E DIGESTIBILIDADE ESTIMADA POR INDICADORES INTERNOS COMPARADOS A COLETA TOTAL
}

\author{
FECAL PRODUCTION AND DIGESTIBILITY ESTIMED BY INTERNAL INDICATORS \\ COMPARED TO THE TOTAL COLLECTION
}

\author{
Silva, F.F. ${ }^{1}$, M.S.M.A. Aguiar², C.M. Veloso ${ }^{1}$, A.J.V. Pires ${ }^{1}$, P. Bonomoํ, V.S. Almeida ${ }^{3}$, R.R. \\ Silva1 ${ }^{1}$, G.G.P. Carvalho ${ }^{3}$, J.A. Marques ${ }^{1}$, A.M. Dias $^{4}$ e L.C.V. Ítavo ${ }^{4}$
}

${ }^{1}$ Universidade Estadual do Sudoeste da Bahia. UESB. Pça Primavera, 40. Bairro Primavera. CEP 45700000.Brasil.rrsilva@uesb.br; cmveloso@uesb.br; aureliano@uesb.br; pbonomo@uesb.br; rrsilva@uesb.br; jdmarques@hotmail.com

${ }^{2}$ Escola Agrotécnica Federal de Guanambi. Brasil. vsazootec@yahoo.com.br

3Universidade Federal de Viçosa. Brasil.vsazootec@yahoo.com.br; gleidsongiordano@yahoo.com.br ${ }^{4}$ Universidade Católica Dom Bosco. Brasil. alezootec@hotmail.com; itavo@ucdb.br

\section{PALAVRAS CHAVE ADICIONAIS}

FDAi. FDNi. Novilhas. Bagaço de mandioca.

\section{RESUMO}

Utilizaram-se 16 novilhas $(3 / 4$ Holandês vs. $1 / 4$ Zebu), para as quais foi fornecida silagem de capim elefante acrescida de bagaço de mandioca como alimento único e, posteriormente, a silagem mais concentrado. Estimou-se a digestibilidade da matéria seca (MS) e da fibra em detergente neutro (FDN) além da produção fecal por meio dos indicadores internos fibra em detergente neutro indigestíveis (FDNi) e fibra em detergente ácido indigestíveis (FDAi), os quais foram comparados ao método da coleta total. A utilização da FDNi para estimar a excreção fecal e digestibilidade da MS e da FDN da silagem apresentou diferença estatística $(p<0,05)$ em relação àquela obtida pela coleta total. A FDNi superestimou a produção fecal e subestimou a digestibilidade da MS e da FDN, o que pode ser atribuído à variabilidade inerente ao material experimental. A excreção fecal estimada pela FDNi e pela FDAi das dietas diferiu estatisticamente $(p<0,05)$ e foi diferente, da obtida pela coleta total. A FDAi superestimou a produção fecal e subestimou a digestibilidade da MS e da FDN e a FDNi subestimou a excreção fecal e superestimou a digestibilidade da MS e da FDN, resultado diferente ao encontrado quando foi estimada a excreção fecal e avaliada a digestibilidade apenas da silagem com diferentes níveis de bagaço de mandioca no presente expe-

Recibido: 22-4-06. Aceptado: 1-4-08.
AdDitional KEYWORDS

ADFi. NDFi. Heifers. Cassava hulls.

rimento. Mais estudos com indicadores, devem ser realizados.

\section{SUMMARY}

Sixteen heifers $(3 / 4$ Holstein vs. $1 / 4$ Zebu) which were feed with elephant grass silage added with cassava hulls as only food and, later, the silage with concentrate. It was estimated the dry matter (DM) and neutral detergent fiber (NDF) digestibility and the fecal production using internal indicators neutral detergent fiber indigestible (NDFi) and acid detergent fiber indigestible (ADFi), which were compared to the total collection method. The use of the NDFi to estimate the fecal excretion and the silage DM and NDF digestibility showed statistical difference $(p<0.05)$ relative to that obtained by the total collection. The NDFi overestimated the fecal production and underestimated the DM and NDF digestibility, what can be attributed to the experimental material inherent variability. The fecal excretion, estimated by the NDFi and ADFi, of the diets differed statistically $(p<0.05)$ and was different to that obtained by total collection. The ADFi overestimated the fecal production and underestimated the DM and NDF digestibility, a result, different of that found when the fecal excretion was estimated and analised the 
digestibility of the silage with different levels of cassava hulls only in the present experiment. More studies with indicators should be realized.

\section{INTRODUÇÃO}

Vários estudos têm sido realizados para medir a digestibilidade e associá-la às características bromatológicas dos alimentos, sendo estas estimadas com relativa facilidade e eficácia (Mertens, 1994). A digestibilidade pode ser obtida pelo método direto, que implica em rigoroso controle de ingestão e excreção diária. Isto levou à idealização de outros métodos, nomeados de métodos indiretos, dos indicadores ou dos marcadores (Silva, 2002). Esses métodos apresentam certas vantagens sobre o da coleta total de fezes, a exemplo da simplicidade e conveniência de utilização.

Objetivou-se com este trabalho analisar os indicadores internos fibra em detergente neutro e fibra em detergente ácido indigestível, por meio da incubação in situ por 144 horas, e estimar a produção fecal, a digestibilidade da matéria seca e a fibra em detergente neutro, comparando com o método da coleta total.

\section{MATERIALE MÉTODOS}

Foram utilizadas 16 novilhas $(3 / 4$ Holandês vs. $1 / 4 \mathrm{Zebu}$ ) com peso vivo médio de 144 $\pm 18 \mathrm{~kg}$, e idade média de 15 meses.

As novilhas foram pesadas e distribuídas, com delineamento inteiramente casualizado, em 4 tratamentos e 4 repetições, definidos conforme a alimentação. Os tratamentos consistiram em 4 dietas com concentrado padronizado para terem o mesmo teor protéico (14\%) e, como volumoso, silagem de capim-elefante cortado com 80 dias de idade com 5, 10, 15 e $20 \%$ de bagaço de mandioca, na base da matéria natural.

Os animais foram alimentados diariamente pela manhã às 8:00 h e à tarde às 16:00 h com dieta, conforme a fase do experimento, silagem e, posteriormente, silagem + con- centrado. Maiores informações sobre consumo e relação volumoso:concentrado consultar Silva et al. (2007).

Os animais foram submetidos a um período de avaliação (14 dias), no qual as silagens foram fornecidas como alimento único, sendo assim, determinadas e estimadas a digestibilidade da matéria seca (MS) e da fibra em detergente neutro (FDN) destas silagens e a produção fecal. Os sete primeiros dias foram de adaptação e os subseqüentes consistiram no período experimental (coleta de amostras de alimento, sobras e fezes).

Da mesma forma, na sexta semana, com sete dias de adaptação mais sete de coletas, foi determinada a digestibilidade das dietas (silagem + concentrado). As fezes foram amostradas, sendo no primeiro dia pela manhã, e, no segundo pela tarde. Na coleta total foi coletada uma amostra composta por animal e foram amostrados $10 \%$ do total coletado em 48 horas e, posteriormente, présecas e moídas em moinho com peneira de malha de 1,0 $\mathrm{mm}$, para posteriores análises laboratoriais e comparações.

Para determinação dos teores de marcadores internos utilizou-se a técnica in situ, com dois bovinos machos $(3 / 4$ Holandês $v s$. $1 / 4 \mathrm{Zebu}$ ), fistulados no rúmen. As amostras do fornecido (silagem e concentrado), das sobras e das fezes, secas e moídas, foram colocadas em sacos de Ankon em triplicata, os quais foram introduzidos nas fístulas dos bovinos. Após o período de incubação de 144 horas, os sacos foram removidos, lavados e as amostras foram submetidas à análise de FDNi e FDAi, determinadas pelo método seqüencial de Robertson e Van Soest (1981).

As médias foram comparadas por meio do teste Dunnett, à 5\%, utilizando o SAEG (2001).

\section{RESULTADOSEDISCUSSÃO}

Não foi observado efeito da adição do bagaço de mandioca na silagem do capimelefante, os dados foram comparados utili- 


\section{ESTIMAÇAO DA PRODUÇÃO FECAL E DIGESTIBILIDADE}

zando-se a média global dos quatro tratamentos.

A FDNi superestimou a produção fecal e subestimou a digestibilidade da MS e da FDN. Isso pode ser atribuído à variabilidade inerente ao material experimental.

A utilização de FDAi como indicador levou à superestimativa da excreção fecal das silagens (tabela I).

Os valores médios de recuperação fecal e digestibilidade da matéria seca e da fibra em detergente neutro dos indicadores FDNi e FDAi para as dietas contendo silagens com diferentes níveis de bagaço de mandioca e concentrado encontram-se na tabela II.

As excreções fecais estimadas por FDNi e FDAi foram diferentes entre si e em relação à excreção fecal pela coleta total $(p<0,05)$. A FDAi superestimou a produção fecal e subestimou a digestibilidade da MS e da FDN; a FDNi subestimou a excreção fecal e superestimou a digestibilidade da MS e da FDN, resultado diferente ao encontrado quando foi estimada a excreção fecal e avaliada a digestibilidade apenas da silagem com diferentes níveis de bagaço de mandioca no presente experimento, confirmando assim que mais estudos em relação aos indicadores devem ser realizados para identificação dos fatores responsáveis pelas respostas variáveis, possibilitando melhor padronização das metodologias.

Os coeficientes de digestibilidade da MS e da FDN das dietas não diferiram $(\mathrm{p}<0,05)$ em relação ao nível de bagaço de mandioca na silagem de capim elefante, independentemente do indicador interno utilizado (tabela II). Os valores dos coeficientes de digestibilidade da MS e da FDN, observados com o uso dos indicadores internos FDNi e FDAi, diferiram $(p>0,05)$ dos valores observados com o uso do método da coleta total de fezes. Berchielli et al. (2000), utilizando bovinos machos alimentados com milho e farelo de soja, tendo como volumoso silagem de milho ou de milho híbrido, verificaram que os indicadores FDNi e FDAi apresentaram resultados

Tabela I. Valores médios de excreção fecal e digestibilidade da matéria seca e da fibra em detergente neutro determinados pela coleta total de fezes e estimados pela fibra em detergente neutro indigestivel (FDNi) das silagens com diferentes níveis de bagaço de mandioca. (Average values of fecal excretion and digestibility of the dry matter and the neutral detergent fiber determined by the total excrement collection and estimated by the neutral detergent indigestive fiber (FDNi) of ensilages with different cassava residue levels).

\begin{tabular}{lccccc}
\hline & Nível de bagaço de mandioca na silagem (\%) & \\
& 5 & 10 & 15 & 20 & Média \\
\hline Excreção fecal (kg/dia) & & & & & \\
$\quad$ Coleta total & 2,56 & 2,22 & 2,47 & 2,18 & $2,36^{\mathrm{c}}$ \\
$\quad$ FDNi & 2,74 & 2,70 & 3,19 & 3,16 & $2,95^{\mathrm{b}}$ \\
$\quad$ FDAi & 5,90 & 4,95 & 5,46 & 5,20 & $5,38^{\mathrm{a}}$ \\
Digestibilidade da matéria seca (\%) & & & & & \\
$\quad$ Coleta total & 53,42 & 58,84 & 56,05 & 58,80 & $56,77^{\text {a }}$ \\
$\quad$ FDNi & 51,54 & 51,42 & 47,28 & 46,17 & $49,10^{\mathrm{b}}$ \\
Digestibilidade da fibra em detergente neutro (\%) & & & & & \\
$\quad$ Coleta total & 50,10 & 51,00 & 39,36 & 42,60 & $45,76^{\text {a }}$ \\
$\quad$ FDNi & 45,77 & 39,05 & 22,24 & 17,90 & $31,24^{\text {b }}$ \\
\hline
\end{tabular}

*Médias seguidas da mesma letra da testemunha (coleta total), não diferem desta pelo teste Dunnet a $5 \%$ de probabilidade. 
Tabela II. Valores médios para excreção fecal e digestibilidade da matéria seca e da fibra em detergente neutro pela coleta total de fezes e estimados pela fibra em detergente neutro indigestivel (FDNi) e fibra em detergente ácido indigestivel (FDAi) das dietas contendo silagens com diferentes níveis de bagaço de mandioca e concentrado. (Average values for fecal excretion and digestibility of the dry matter and the neutral detergent fiber in the total excrement collection and estimated by the indigestible neutral detergent fiber (FDNi) and indigestible acid detergent fiber (FDAi) of the diets containing ensilages with different levels of cassava residue and concentrate).

\begin{tabular}{|c|c|c|c|c|c|}
\hline & \multicolumn{5}{|c|}{ Nível de bagaço de mandioca na silagem (\%) } \\
\hline & 5 & 10 & 15 & 20 & Média \\
\hline \multicolumn{6}{|c|}{ Excreção fecal (kg/dia) } \\
\hline Coleta total & 4,38 & 4,24 & 5,05 & 3,84 & $4,38^{b}$ \\
\hline FDNi & 4,14 & 3,46 & 3,60 & 2,60 & $3,45^{\mathrm{c}}$ \\
\hline FDAi & 4,62 & 4,84 & 5,70 & 4,39 & $4,89^{a}$ \\
\hline \multicolumn{6}{|c|}{ Digestibilidade da matéria seca (\%) } \\
\hline Coleta total & 60,93 & 65,00 & 67,68 & 66,34 & $64,98^{\mathrm{b}}$ \\
\hline $\mathrm{FDNi}$ & 63,13 & 71,36 & 77,47 & 78,11 & $72,52^{\mathrm{a}}$ \\
\hline FDAi & 59,04 & 59,85 & 64,08 & 62,50 & $61,36^{c}$ \\
\hline \multicolumn{6}{|c|}{ Digestibilidade da fibra em detergente neutro (\%) } \\
\hline Coleta total & 40,94 & 49,88 & 44,58 & 42,51 & $44,47^{\mathrm{b}}$ \\
\hline FDNi & 45,04 & 56,85 & 58,79 & 62,60 & $55,82^{a}$ \\
\hline FDNi & 45,04 & 56,85 & 58,79 & 62,60 & $55,82^{a}$ \\
\hline
\end{tabular}

*Médias seguidas da mesma letra da testemunha (coleta total), não diferem desta pelo teste Dunnet, a $5 \%$ de probabilidade.

semelhantes na estimativa da digestibilidade aos da coleta total de fezes quando incubados durante seis dias (144 horas) in vitro.

\section{CONCLUSÕES}

Os indicadores internos FDNi e FDAi

\section{BIBLIOGRAFIA}

Berchielli, T.T., P. Andrade e C.L. Furlan. 2000. Avaliação de indicadores internos em ensaios de digestibilidade. Rev. Bras. Zootecn., 29: 830833.

Mertens, D.R. 1994. Regulation of forage intake. In: Fahey, G.C., M. Collins, D.R. Mertens, L.E. Moser. (eds). Forage quality evaluation. Madison: ASA. CSSA, SSSA. p. 450-493.

Robertson, J.B. and P.J Van Soest. 1981. The detergent system of analysis and its application to human foods. In: James, W.P.T., O. Theanderm. (Eds). The analysis of dietary fiber in food. New York: Marcel Dekker. p. 123-158. não fornecem estimativas confiáveis da excreção fecal e da digestibilidade de MS e da FDN. Necessitam-se de avaliações sistemáticas que permitam padronização das metodologias e reconhecimento de suas limitações.

Silva, D.J. 2002. Análise de alimentos: métodos químicos e biológicos. Universidade Federal de Viçosa. Viçosa-MG. Brasil. 235 p.

Silva, F.F., M.S.M.A. Aguiar, C.M. Veloso, A.J.V. Pires, P. Bonomo, G.S. Dutra, V.S. Almeida, G.G.P. Carvalho, R.R. Silva, A.M. Dias e L.C.V. Ítavo. 2007. Bagaço de mandioca na ensilagem do capim-elefante: qualidade das silagens e digestibilidade dos nutrientes. Arq. Bras. Med. Vet. Zoo., 59: 719-729.

SAEG. 2001. Sistema de análises estatísticas e genéticas. UFV-Universidade Federal de Viçosa. Viçosa-MG. Brasil.

Archivos de zootecnia vol. 58, núm. 224, p. 744. 